\title{
ChemComm
}

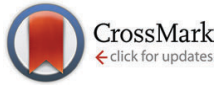

Cite this: Chem. Commun., 2016, 52,6379

Received 17th March 2016, Accepted 12th April 2016

DOI: $10.1039 / c 6 c c 02349 e$

www.rsc.org/chemcomm

\section{Highly photoluminescent copper carbene complexes based on prompt rather than delayed fluorescence $\dagger$}

\author{
Alexander S. Romanov, ${ }^{a}$ Dawei Di, ${ }^{\mathrm{b}}$ Le Yang, ${ }^{\mathrm{b}}$ Julio Fernandez-Cestau, ${ }^{\mathrm{a}}$ \\ Ciaran R. Becker, ${ }^{a}$ Charlotte E. James, ${ }^{a}$ Bonan Zhu, ${ }^{b}$ Mikko Linnolahti, *c \\ Dan Credgington ${ }^{\mathrm{b}}$ and Manfred Bochmann*a
}

\begin{abstract}
Linear two-coordinate copper complexes of cyclic (alkyl)(amino)carbenes (CAAC)CuX ( $\mathrm{X}=$ halide) show photoluminescence with solid-state quantum yields of up to $96 \%$; in contrast to previously reported $\mathrm{Cu}$ photoemitters the emission is independent of temperature over the range $T=4-300 \mathrm{~K}$ and occurs very efficiently by prompt rather than delayed fluorescence, with lifetimes in the subnanosecond range.
\end{abstract}

Photoemissive complexes of copper(I) have been intensely investigated, not least in connection with possible applications as phosphors in organic light-emitting diodes (OLEDs). ${ }^{1,2}$ These are typically three- and four-coordinate complexes based on phosphine and heterocyclic ligands with good $\pi$-acceptor properties. Here, high coordination numbers and polynuclear halide-bridged structures have proved advantageous in minimising non-radiative decay, resulting in high quantum yields via the well-known "thermally activated delayed fluorescence" (TADF) emission pathway. ${ }^{1-3}$ More recently, three-coordinate copper complexes which oscillate between TADF and phosphorescence ${ }^{4}$ or show mixed emissions ${ }^{5}$ have also been described, with intrinsic exciton lifetimes of the order of 10-20 $\mu \mathrm{s}^{6}{ }^{6}$ For efficient OLEDs and phosphors, the emission lifetimes should be as short as possible to compete with non-radiative relaxation and to minimise self-quenching effects. Short lifetimes also allow for fast switching, enabling high optical data transfer rates. ${ }^{7}$

During recent studies on the oxidative addition reactions of gold(I) complexes stabilized by cyclic (alkyl)(amino)carbene (CAAC) ligands, we found that these compounds are unusually photosensitive. ${ }^{8}$ CAAC ligands are of course well-known for

\footnotetext{
${ }^{a}$ School of Chemistry, University of East Anglia, Earlham Road, Norwich, NR4 7TJ, UK. E-mail: m.bochmann@uea.ac.uk

${ }^{b}$ Department of Physics, Cavendish Laboratory, Cambridge University, Cambridge CB3 OHE, UK

${ }^{c}$ Department of Chemistry, University of Eastern Finland, Joensuu Campus,

FI-80101 Joensuu, Finland

$\dagger$ Electronic supplementary information (ESI) available. CCDC 1469283 (for 1a), 1469285 (for 1b) and 1469284 (for 1c). For ESI and crystallographic data in CIF or other electronic format see DOI: 10.1039/c6cc02349e
}

their strong $\sigma$-donor properties and have been used in numerous catalytic reactions ${ }^{9}$ but their photophysical properties have so far not been explored. We report here the synthesis, structure and photoluminescence properties of two-coordinate, monomeric CAAC copper and gold halide complexes. The copper compounds reach quantum yields of up to $96 \%{ }^{10}$ By contrast, analogous imidazolylidene-based $\mathrm{NHC} \mathrm{Cu}$ and $\mathrm{Au}$ halide complexes are non-emissive. ${ }^{11}$ The ease of synthesis, good solubility in organic solvents, high thermal stability and non-self-quenching characteristics makes these complexes very promising as display phosphors and for incorporation into OLEDs. The complexes were prepared according to eqn (1).

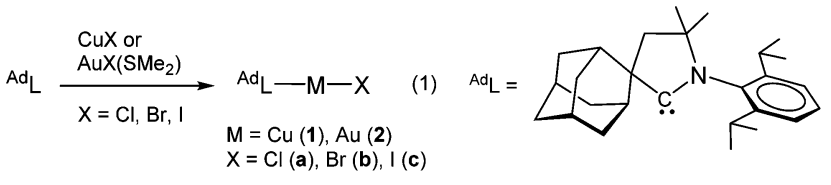

The compounds $\left({ }^{\mathrm{Ad}} \mathrm{L}\right) \mathrm{MX}(\mathrm{M}=\mathrm{Cu}, \mathrm{Au} ; \mathrm{X}=\mathrm{Cl}, \mathrm{Br}, \mathrm{I})$ are obtained in high yields. They show good solubility in polar nonprotic solvents (dichloromethane, THF), are moderately soluble in toluene and insoluble in hexane. They are thermally very stable and can be sublimed at $200{ }^{\circ} \mathrm{C} / 0.3 \mathrm{mmHg}$ without decomposition. The thermal stability of the $\mathrm{Cu}$ and $\mathrm{Au}$ complexes as powders was determined by thermal gravimetric analysis (TGA) and differential scanning calorimetry (DSC) (for decomposition temperatures $T_{\mathrm{d}}$ and melting points $T_{\mathrm{m}}$ see ESI, $\dagger$ Table S1). The compounds melt above $270{ }^{\circ} \mathrm{C}$, e.g. $\left({ }^{\mathrm{Ad}} \mathrm{L}\right) \mathrm{CuCl}$ melts at $280{ }^{\circ} \mathrm{C}$ and decomposes above $328{ }^{\circ} \mathrm{C}$.

Crystals of the copper halide complexes 1a-c suitable for X-ray diffraction were obtained by layering of $\mathrm{CH}_{2} \mathrm{Cl}_{2}$ solutions with hexanes. The $\mathrm{Cu}$ complexes are two-coordinate and monomeric and crystallize with two independent molecules in the unit cell.\$ The deviation of the $\mathrm{C}-\mathrm{Cu}-\mathrm{X}$ moiety from linearity decreases in the sequence $\mathrm{Cl}>\mathrm{Br}>\mathrm{I}$, with angles of 175.33(5), 177.59(11) and 178.52(5) ${ }^{\circ}$, respectively (see ESI, $\dagger$ for details). The complexes show weak intermolecular $\mathrm{C}-\mathrm{H} \cdots \mathrm{Hal}$ interactions. 
Although CAACs are based on a saturated hydrocarbon skeleton, upon UV irradiation the free carbene shows blue fluorescence in the solid state, with a major emission band at $\lambda_{\text {em }}=447 \mathrm{~nm}$ (lifetime $\tau=38.2 \pm 0.1 \mathrm{~ns}$ ), with low photoluminescence quantum yield (PLQY), $\Phi_{\mathrm{PL}}=9.1 \%$; there is also a very weak emission at $660 \mathrm{~nm}$ (see ESI, $\dagger$ Fig. S1). Based on density functional theory (DFT) and time-dependent density functional theory (TD-DFT) calculations we assign these emissions to $\mathrm{S}_{1} \rightarrow \mathrm{S}_{0}$ and $\mathrm{T}_{1} \rightarrow \mathrm{S}_{0}$ transitions $\left(\lambda_{\mathrm{em}}^{\mathrm{calc}}=413\right.$ and $667 \mathrm{~nm}$, respectively, allowing for geometric relaxation of the excited state).

The UV/vis absorption spectra of the copper and gold halide complexes in THF solutions show absorptions below $300 \mathrm{~nm}$ due to an intra-ligand transition of the CAAC ligand, as well as broad bands at 317 to $365 \mathrm{~nm}$ (see ESI, $\uparrow$ Fig. S2 and S3). As DFT calculations show, the HOMO of the halide complexes changes from metal-halide $\sigma$ for $\mathrm{X}=\mathrm{Cl}$ to metal-halide $\sigma^{*}$ (for $\mathrm{X}=\mathrm{I}$ ) (Fig. 1; see also ESI, $\dagger$ Fig. S4). The low energy bands are assigned to a $(\sigma+\mathrm{X})-\pi^{*}$ charge transfer process, ${ }^{12}$ with only minor contribution from the metal. The photoexcitation in these complexes differs therefore from that observed in many copper halide complexes with phosphinopyridine-type ligands, which show predominantly metal-ligand charge transfer. ${ }^{1,2,4,5}$

The redox potentials of $\mathbf{1}$ and $\mathbf{2}$ as determined by cyclic voltammetry, show one irreversible $(\mathrm{X}=\mathrm{Cl}, \mathrm{Br})$ or partially reversible $(\mathrm{X}=\mathrm{I})$ reduction process which is centred on the metal atom. The reduction process becomes reversible in THF, as was previously noted for $\left({ }^{\mathrm{Cy}} \mathrm{CAAC}\right) \mathrm{AuCl} .{ }^{13}$ Oxidation of $\mathbf{1}$ and 2 exhibit one irreversible oxidation wave. The onset oxidation potential for gold halides shows more pronounced cathodic shift in the range $\mathrm{Cl}<\mathrm{Br}<\mathrm{I}$. This suggests a greater contribution by the halide orbitals to the HOMO's energy level (see ESI, $\dagger$ Table S4).

The crystalline complexes display strong photoluminescence on excitation with UV light $\left(\lambda_{\mathrm{ex}}=365 \mathrm{~nm}\right)$ (Table 1). Complex 1a reaches a quantum yield of $96 \%$; this compound shows a remarkably small geometric distortion in the excited state (Fig. 1c and d) which may contribute to the high emission efficiency. The complexes $\left({ }^{\mathrm{Ad}} \mathrm{L}\right) \mathrm{CuX}$ appear to be the first examples of highly luminescent linear copper halides and show a bluishwhite emission which is independent of $\mathrm{X}=\mathrm{Cl}, \mathrm{Br}$ or $\mathrm{I}$. In contrast, the photoluminescence of the gold halides $\mathbf{2 a - 2 c}$ a)

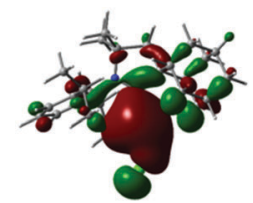

(c)

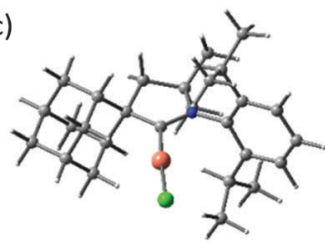

(b)

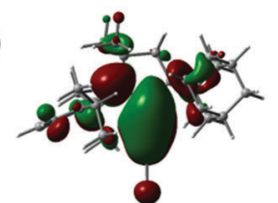

(d)

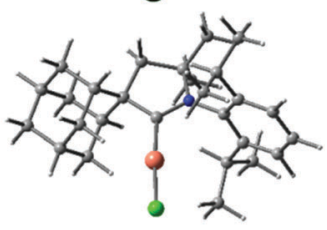

Fig. $1 \mathrm{HOMO}(\mathrm{a}), \mathrm{LUMO}(\mathrm{b})$ and geometry-optimised excited state structures $\mathrm{T}_{1}(\mathrm{c})$ and $\mathrm{S}_{1}(\mathrm{~d})$ of $\left({ }^{\mathrm{Ad}} \mathrm{L}\right) \mathrm{CuCl}(\mathbf{1 a})$.
Table 1 Photophysical properties of $\left({ }^{A d} \mathrm{~L}\right) \mathrm{MX}$ complexes

\begin{tabular}{|c|c|c|c|}
\hline \multirow[b]{2}{*}{ Complex } & \multirow{2}{*}{$\begin{array}{l}\lambda_{\mathrm{abs}}[\mathrm{nm}]\left(10^{3} \varepsilon / \mathrm{M}^{-1} \mathrm{~cm}^{-1}\right), \\
\text { THF }\end{array}$} & \multicolumn{2}{|l|}{ Solid state } \\
\hline & & $\lambda_{\mathrm{em}}\left(\lambda_{\mathrm{exc}}\right)[\mathrm{nm}]$ & $\Phi_{\mathrm{PL}}^{a}$ \\
\hline $1 \mathbf{a}$ & $290(2.2), 365(0.2)$ & $453(300-420)$ & 0.96 \\
\hline $\mathbf{1 b}$ & $291(7.8), 357(0.4)$ & $454(300-420)$ & 0.61 \\
\hline 1c & $298(5.8), 352(0.4)$ & $460(300-420)$ & 0.28 \\
\hline $2 \mathbf{a}$ & 251 (7.6), $269(\mathrm{sh}, 4.1), 317(0.2)$ & $412(280-375)$ & 0.09 \\
\hline $2 \mathbf{b}$ & $257(6.6), 284(3.6), 316(0.7)$ & $480(280-375)$ & 0.13 \\
\hline $2 c$ & $272(5.1), 315(4.2)$ & $516(280-375)$ & 0.18 \\
\hline
\end{tabular}

${ }^{a}$ Quantum yields determined by using an integrating sphere.

shows a ligand-dependent red-shift, in the order $\mathrm{X}=\mathrm{Cl}$ (blue) $<\operatorname{Br}$ (yellow-white) $<$ I (yellow) (Fig. 2).

Photoemission by a TADF mechanism is characterised by a temperature-dependent blue shift, due to triplet-to-singlet upconversion, $\Delta E\left(\mathrm{~S}_{1}-\mathrm{T}_{1}\right)>0 .{ }^{1-5}$ This process requires that the energy difference between the $S_{1}$ and $T_{1}$ excited states is sufficiently small, $\Delta E \approx k_{\mathrm{B}} T$, to allow effective thermal population of both the $T_{1}$ and $S_{1}$ states. Since decay from $S_{1}$ is much faster than from $T_{1}$, the emission process is predominantly channelled via $\mathrm{S}_{1}$, with the delayed emission rate limited by the rate of inter-system crossing (ISC). Copper photoemitters have become synonymous with the TADF process. However, while this process provides an effective light harvesting mechanism from emitters for which radiative decay from the triplet state is forbidden, it is typically achieved by reducing the overlap between electron and hole orbitals, leading to low oscillator strengths and low radiative decay. ${ }^{14}$

Given the ample precedent for the TADF decay mechanism in copper complexes, it was surprising to find that the photoemissions of 1a-c over the range of 4-300 $\mathrm{K}$ proved to be independent of temperature (see ESI, $\dagger$ Fig. S7). The normalised PL decay curves (Fig. 3a) for 1a at different temperatures, as determined by time-correlated single photon counting (TCSPC),

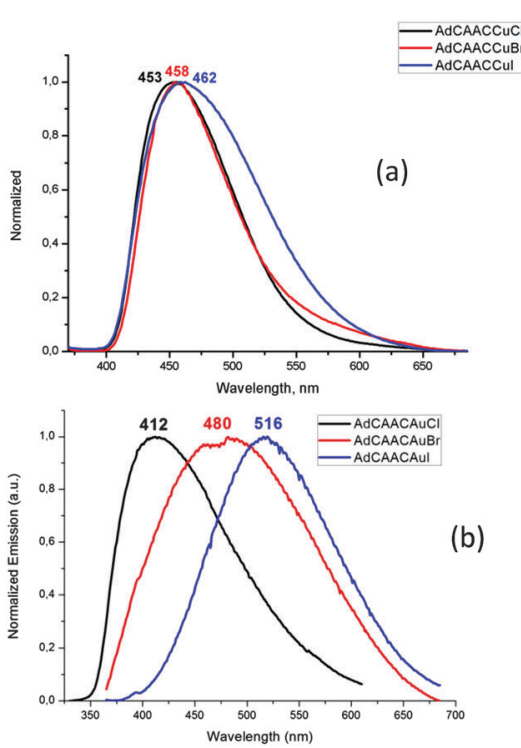

Fig. 2 Emission spectra of (a) $\left({ }^{\mathrm{Ad}} \mathrm{L}\right) \mathrm{CuX}$ and (b) $\left({ }^{\mathrm{Ad}} \mathrm{L}\right) \mathrm{AuX}(\mathrm{X}=\mathrm{Cl}, \mathrm{Br}, \mathrm{I})$ in the solid state (excited at $\lambda_{\mathrm{ex}}=365 \mathrm{~nm}$ ). 

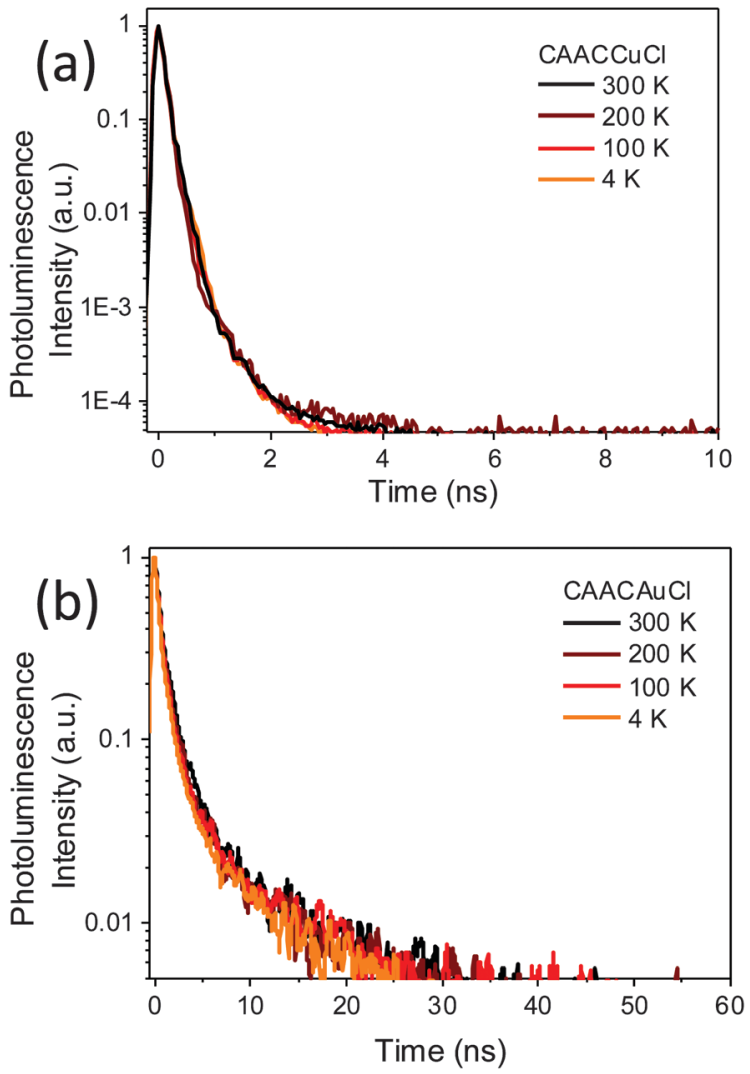

Fig. 3 Normalised PL decay showing singlet prompt decay at different temperatures for (a) $\mathbf{1 a}$, and (b) $\mathbf{2 a}$

show that the emission is due to prompt fluorescence over 3 orders of magnitude, with a temperature-independent lifetime of only $0.22-0.3 \mathrm{~ns}$ (see ESI, $\dagger$ Fig. S8). This is close to the instrument response function width of $0.2 \mathrm{~ns}$. The corresponding fluorescence decay rate is therefore at least $3.3-5 \times 10^{9} \mathrm{~s}^{-1}$ for $\mathbf{1 a}$. There was no evidence for either delayed fluorescence or phosphorescence. As far as we are aware this is by far the highest fluorescence rate for an efficient copper-based photoemitter. Considering PLQY $=k_{\mathrm{r}} /\left(k_{\mathrm{r}}+k_{\mathrm{nr}}\right)$, where $k_{\mathrm{r}}$ is the fluorescence rate constant and $k_{\mathrm{nr}}$ is the rate of the non-radiative process incorporating both non-radiative singlet decay and ISC, we estimate a lower bound of $2 \times 10^{8} \mathrm{~s}^{-1}$ for $k_{\mathrm{nr}}$ in $\mathbf{1 a}$.

Emission from the gold complexes 2 is also predominantly via temperature-independent prompt emission, though with substantially weaker PL, with lifetime of $\sim 0.5 \mathrm{~ns}$ (as shown for $2 \mathrm{a}$ in Fig. 3b). A fluorescence rate of about $2 \times 10^{8} \mathrm{~s}^{-1}$ can be estimated from its PLQY (0.09), much slower than the fluorescence rate of its $\mathrm{Cu}$ counterpart. The competing nonradiative decay rate is approximately $2 \times 10^{9} \mathrm{~s}^{-1}$. There was no significant change in PL lifetime on cooling (see ESI, $\dagger$ Fig. S8) and, despite the presence of $\mathrm{Au}$, there is no clear evidence for phosphorescence from this emitter. Since coinage metal complexes tend to exhibit strong spin-orbit coupling, sufficient to allow ISC on sub-ps timescales, ${ }^{15}$ the high fluorescence yield, lack of phosphorescence and magnitude of $k_{\mathrm{nr}}$ are surprising.
Table 2 Excitation energies ( $\mathrm{kJ} \mathrm{mol}^{-1}$ ) of halide complexes 1 and 2 in geometries optimized for the singlet and triplet excited states

\begin{tabular}{llll}
\hline Complex & $\mathrm{T}_{1}$ & $\mathrm{~S}_{1}$ & $\mathrm{~S}_{1}-\mathrm{T}_{1}$ \\
\hline $\mathbf{1 a}$ & 248.0 & 285.5 & 37.5 \\
$\mathbf{1 b}$ & 249.0 & 288.4 & 39.4 \\
$\mathbf{1 c}$ & 249.3 & 285.4 & 36.1 \\
$\mathbf{2 a}$ & 288.6 & 327.0 & 38.4 \\
$\mathbf{2 b}$ & 281.9 & 318.4 & 36.5 \\
$\mathbf{2 c}$ & 270.5 & 300.0 & 29.4
\end{tabular}

The unusual photophysical behavior was investigated with the aid of DFT and TD DFT calculations. The results reproduce the observed halide dependence of the excited state levels for the gold compounds and the lack of such ligand dependence in the case of copper. A comparison of the ground state and excited state geometries of $\mathbf{1 a - 1 c}$ and $\mathbf{2 a - 2 c}$ is given in Table 2 (see also ESI, $\dagger$ Fig. S5). The excited state structure of the copper chloride 1a shows a remarkably small deviation from linearity (Fig. 1c and d); in fact the calculated $\mathrm{C}$ (carbene)-Cu-Cl angles in the $T_{1}$ and $S_{1}$ states (175.8 and $176.2^{\circ}$, respectively, see ESI, $\dagger$ Table S2) are essentially identical to the experimentally determined angle in the crystal $\left(175.33(5)^{\circ}\right)$. This aspect may contribute to the very high solid-state quantum yield. The excited states of $\mathbf{1 b}$ and $\mathbf{1 c}$ show more deviation from linearity, though not altering the identity of the LUMO (ESI, $\dagger$ Fig. S6), which leads to similar emission energies (Fig. 2a). The $S_{1}-T_{1}$ energy difference of $30-40 \mathrm{~kJ} \mathrm{~mol}^{-1}$ is at the high end of values where a TADF process can be expected to operate, in agreement with the observation of prompt rather than delayed fluorescence from the $S_{1}$ state in these copper halide complexes. Whereas the $\mathrm{Au}$ analogues show only slightly smaller $\mathrm{S}_{1}-\mathrm{T}_{1}$ energy differences, the $\mathrm{C}-\mathrm{M}-\mathrm{X}$ angles in the $\mathrm{S}_{1}$ and $\mathrm{T}_{1}$ states are much more acute (ESI, $\dagger$ Table S2), in line with the lower radiative decay rate of 2a-c. Spin mixing is most effective when singlet and triplet excited states exist which are near-degenerate. ${ }^{15}$ However, $\mathrm{T}_{2}$ energies are calculated to be about $0.3 \mathrm{eV}$ above $\mathrm{S}_{1}$ for all compounds, consistent with slower ISC.

In coordinating solvents like THF the photoemissions of the copper halides 1a-c show a solvent-induced red-shift of $>130 \mathrm{~nm}$. DFT calculations confirmed that while there is no THF coordination to the ground states of $\mathbf{1 a}, \mathbf{b}$ and $\mathbf{2 a - c}$, the binding energies to the $T_{1}$ states are significant and are stronger for copper than for gold (see ESI, $\dagger$ Table S3). $\S$ The solvent-induced red-shift was therefore traced to emission from a three-coordinate solvent exciplex.

In conclusion, cyclic (alkyl)(amino)carbenes were found to be unexpectedly photoactive and give rise to linear, monomeric copper complexes which display photoluminescence quantum yields of up to $96 \%$. Unlike three- and four-coordinate photoemissive copper complexes, for which high quantum yields have been correlated with temperature-dependent delayed fluorescence and which give decay lifetimes of several microseconds, the complexes reported here show temperatureindependent prompt fluorescence, with decay times that are three to four orders of magnitude faster. This is sufficient to avoid ISC. Since triplet states are not involved, there is no 
requirement for dispersion to avoid self-quenching. ${ }^{16}$ The complexes are thermally very stable and sufficiently soluble and volatile for use in the fabrication of light-emitting devices by solution processing or vapor phase deposition techniques. Together with the short excitation lifetimes, these properties open up the possibility of constructing inorganic and organic LED devices with very high bandwidth based on phosphors made from linear CAAC coinage metal complexes.

This work was supported by the ERC, the Royal Society, and by the Academy of Finland (Project 251448). M. B. is an ERC Advanced Investigator Award holder (grant no. 338944-GOCAT). The computations were made possible by use of the Finnish Grid Infrastructure resources.

\section{Notes and references}

\$ For the structures of the gold complexes 2 see ref. 8 .

$\S$ Complex 1c is an exception and makes a weak 3-coordinate THF complex in the ground state, $\Delta E=-9.2 \mathrm{~kJ} \mathrm{~mol}^{-1}$.

1 M. Wallesch, D. Volz, C. Fléchon, D. M. Zink, S. Bräse and T. Baumann, Organic Light Emitting Materials and Devices XVIII, ed. F. So, Proc. of SPIE 2014, 9183, paper 918309.

2 H. Yersin, A. F. Rausch, R. Czerwieniec, T. Hofbeck and T. Fischer, Coord. Chem. Rev., 2011, 255, 2622.

3 H. Uoyama, K. Goushi, K. Shizu, H. Nomura and C. Adachi, Nature, 2012, 492, 234.

4 M. J. Leitl, V. A. Krylova, P. I. Djurovich, M. E. Thompson and H. Yersin, J. Am. Chem. Soc., 2014, 136, 16032, and cited references.
5 T. Hofbeck, U. Monkowius and H. Yersin, J. Am. Chem. Soc., 2015, 137, 399.

6 For other examples see also: (a) R. Marion, F. Sguerra, F. DiMeo, E. Sauvageot, J. F. Lohier, R. Daniellou, J. L. Renaud, M. Linares, M. Hamel and S. Gaillard, Inorg. Chem., 2014, 53, 9181; (b) M. Osawa, Chem. Commun., 2014, 50, 1801; (c) V. A. Krylova, P. I. Djurovich, B. L. Conley, R. Haiges, M. T. Whited, T. J. Williams and M. E. Thompson, Chem. Commun., 2014, 50, 7176; (d) M. Wallesch, D. Volz, D. M. Zink, U. Schepers, M. Nieger, T. Baumann and S. Bräse, Chem. - Eur. J., 2014, 20, 6578, and cited refs.

7 J. Clark and G. Lanzani, Nat. Photonics, 2010, 4, 438.

8 A. S. Romanov and M. Bochmann, Organometallics, 2015, 34, 2439.

9 M. Soleilhavoup and G. Bertrand, Acc. Chem. Res., 2015, 48, 256.

10 For reviews of photoemissive carbene complexes see: (a) R. Visbal and M. C. Gimeno, Chem. Soc. Rev., 2014, 43, 3551; (b) L. Mercs and M. Albrecht, Chem. Soc. Rev., 2010, 39, 1903.

11 (a) V. J. Catalano, A. L. Moore, J. Shearer and J. Kim, Inorg. Chem., 2009, 48, 11362; (b) L. Ray, M. M. Shaikh and P. Ghosh, Inorg. Chem., 2008, 47, 230-240.

12 (a) M. Osawa, M. Hoshino, M. Hashimoto, I. Kawata, S. Igawa and M. Yashima, Dalton Trans., 2015, 44, 8369; (b) M. Hashimoto, M. Igawa, M. Yashima, I. Kawata, M. Hoshino and M. Osawa, J. Am. Chem. Soc., 2011, 133, 10348.

13 D. S. Weinberger, M. Melaimi, C. E. Moore, A. L. Rheingold, G. Frenking, P. Jerabek and G. Bertrand, Angew. Chem., Int. Ed., 2013, 52, 8964.

14 Q. Zhang, T. Komino, S. Huang, S. Matsunami, K. Goushi and C. Adachi, Adv. Funct. Mater., 2012, 22, 2327.

15 R. A. Vogt, T. G. Gray and C. E. Crespo-Hernández, J. Am. Chem. Soc., 2012, 134, 14808.

16 (a) H. Xu, R. Chen, Q. Sun, W. Lai, Q. Su, W. Huang and X. Liu, Chem. Soc. Rev., 2014, 43, 3259; (b) H. Flügge, A. Rohr, S. Döring, C. Fléchon, M. Wallesch, D. Zink, J. Seeser, J. Leganés, T. Sauer, T. Rabe, W. Kowalsky, T. Baumann and D. Volz, Proc. SPIE, 2015, 9566, 95661. 